\title{
Normativizando o comer: análise crítica de guias alimentares brasileiros e espanhóis no contexto da pandemia de COVID-19
}

\author{
Standardizing eating habits: a critical analysis of Brazilian \\ and Spanish food guides in the context of the COVID-19 pandemic
}

Ursula Peres Verthein (https://orcid.org/0000-0002-1304-9642) ${ }^{1}$

Maria Clara de Moraes Prata Gaspar (https://orcid.org/0000-0002-1517-4981) ${ }^{1}$
${ }^{1}$ Observatorio de la Alimentación (Odela), Universitat de Barcelona Ed. Verdaguer. C/ Prat de la Riba 171, Campus de l'Alimentació de Torribera. 08921 Santa Coloma de Gramenet Espanha. ursulaverthein@gmail.com
Abstract In response to the health, social, economic and political impacts caused by the COVID-19 pandemic, several countries have adopted social isolation as a preventive measure. The concern with "healthy" eating was accentuated in this context and food norms were developed as an orientation strategy related to eating habits. The scope of this article is to carry out a critical and comparative analysis of four food guidelines published in Brazil and Spain in this period, based on three principles: concepts regarding healthy eating; the place attributed to the multidimensionality of the act of eating; and the relevance of intersectionality. Comparison of the documents was conducted using a qualitative approach based on discourse analysis. The documents feature differences in terms of the format and content of the recommendations, but the discursive construction of all the guidelines is normative and reproduces a fundamentally biomedical perspective centered on nutrients and on individual responsibility, without taking into consideration the multidimensionality of the act of eating and the specificities of the micro- and macrosocial contexts. The analysis also reveals the need to include the intersectional dimensions of gender, race, ethnicity and class into the proposed recommendations.

Key words Healthy eating, Food norms, COVID-19, Medicalization, Intersectionality
Resumo Em resposta aos impactos sanitário, social, econômico e político causados pela pandemia de COVID-19, diversos países assumiram $o$ isolamento físico como medida preventiva. A preocupação com a alimentação "saudável" acentuou-se neste contexto e guias alimentares foram elaborados como uma estratégia de orientação sobre alimentação. Este artigo tem como objetivo realizar uma análise crítica e comparativa de quatro guias alimentares publicados no Brasil e na Espanha neste período, a partir de três eixos: as concepções sobre o comer saudável, o lugar atribuido à multidimensionalidade do ato alimentar e a relevância da interseccionalidade. A comparação dos documentos efetuou-se a partir de uma abordagem qualitativa baseada na análise do discurso. Os documentos apresentam diferenças quanto ao formato e o conteúdo das recomendações, porém a construção discursiva de todos os guias é normativa e reproduz uma perspectiva fundamentalmente biomédica centrada nos nutrientes e na responsabilização individual, sem considerar com profundidade a multidimensionalidade do ato alimentar $e$ as especificidades dos contextos micro e macrossociais. Revela-se também a necessidade da inclusão das dimensões interseccionais de gênero, raça, etnia e classe nas recomendações propostas.

Palavras-chave Alimentação Saudável, Guia Alimentar, COVID-19, Medicalização, Interseccionalidade 


\section{Introdução}

Em resposta aos impactos sanitário, social, econômico e político causados pela pandemia de COVID-19, um grande número de países assumiu o isolamento físico como medida necessária para a maior parte da população. Nesse contexto, as formas de viver, de se relacionar e o conjunto das práticas cotidianas em geral e das alimentares, em particular foram ressignificadas. Novas injunções sanitárias e sociais, materiais e simbólicas, reconfiguraram as relações com a comida e o comer durante este período ${ }^{1}$.

A Segurança Alimentar e Nutricional (SAN) tornou-se um tema de discussão tanto pelas consequências relacionadas com uma maior dificuldade de acesso aos alimentos e com os efeitos socioeconômicos que acentuaram os processos de precarização $^{2-4}$, como pelas problemáticas associadas às novas práticas alimentares e corporais resultantes do confinamento ${ }^{5}$. A preocupação com a alimentação "saudável" intensificou-se seja pelos aspectos preventivos relacionados ao fortalecimento do sistema imunitário, seja pelas inquietudes associadas à forma corporal e ao ganho de peso, seja pelas crenças de contaminação através do consumo alimentar ${ }^{1}$. O contexto de pandemia acentuou, portanto, a cacofonia alimentar - uma difusão de múltiplos discursos normativos sobre o comer ${ }^{6}$, pois os aspectos higiênicos e nutricionais do ato alimentar tornaram-se mais presentes nos meios de comunicação e redes sociais, assim como nos discursos dos profissionais da saúde e institucionais ${ }^{5,7}$. Nesse caminho, instituições de diversos países elaboraram guias alimentares, como uma estratégia de orientação sobre o que, quanto, como ou quando comer de forma "adequada" e "saudável".

Os guias alimentares são instrumentos que estabelecem as diretrizes em matéria de alimentação e nutrição com o objetivo de orientar as escolhas alimentares, assim como promover uma alimentação saudável e um bom estado de saúde, variando no seu formato, linguagem e conteúdo no tempo e segundo os contextos ${ }^{8-10}$. Dada a importância desses instrumentos na transmissão de normas dietéticas, este trabalho tem como objetivo realizar uma análise crítica e comparativa de guias alimentares publicados no Brasil e na Espanha no contexto da pandemia de COVID-19.

Este estudo parte do pressuposto de que as especificidades de cada um dos países, no que se refere às características demográficas, econômicas, políticas e sociais, lhes confere formas distintas de vivenciar, construir respostas e operar a gestão social e de saúde da pandemia. Nesse sentido, cabe dizer que a leitura analítico-crítica-comparativa entre as duas realidades não tem como objetivo realizar uma contextualização exaustiva da situação social, política ou econômica de cada um deles. A proposta é ler contrastivamente a forma como se construíram os discursos sobre a alimentação, nutrição e saúde nos guias alimentares produzidos por instituições de dois países com alta incidência de casos de COVID-19. Para a realização da análise referida, no contexto brasileiro o estudo analisou o Guia de Orientação em Relação à Alimentação e Exercício Físico diante da COVID-19 (GORAEF) ${ }^{11}$, elaborado pelo Núcleo de Alimentação, Saúde e Ambiente (Nasa/CST/Cogepe/Fiocruz) e o Guia para uma Alimentação Saudável em tempos de COVID-19 $(\mathrm{GAS})^{12}$, elaborado pela Associação Brasileira de Nutrição. Na Espanha, os guias analisados foram: \#QuedateencasaComeBien Ante el Coronavirus SARS-CoV-2 (QCCB) ${ }^{13}$, elaborado pelo Colegio de Dietistas y Nutricionistas de Cataluña e as Recomendaciones de alimentación y nutrición para la población española ante la crisis sanitaria del COVID-19 (RANPE) ${ }^{14}$ da Academia Española de Nutrición y Dietética e do Consejo General de Colegios Oficiales de Dietistas-Nutricionistas.

A perspectiva analítica adotada considera que os discursos nutricionais não são "simples" recomendações que emergem das ciências nutricionais, sem relação com seus contextos. Partimos da compreensão de que esses discursos reproduzem determinadas perspectivas sobre o comer e o comer saudável, exercendo consequências (morais, sociais, culturais, simbólicas) para os atores sociais e a organização social. Consideramos que essas recomendações se inserem portanto em uma lógica contextual e se associam com valores sociais, alinhamentos políticos e ideológicos, exercendo impactos tangíveis na compreensão da individualidade e coletividade, nas relações sociais e ações cotidianas que governam os corpos e suas disciplinas ${ }^{15-19}$.

Este trabalho se inscreve numa perspectiva teórica pós-estruturalista, principalmente fundamentada no pensamento de Foucault ${ }^{20,21}$, que analisa as conexões entre processos sociais, discurso e relações de poder. Consideramos essa perspectiva relevante para as discussões que se realizam no campo da nutrição, como as que têm sido abordadas através dos Estudos Críticos de Nutrição/Dietética ${ }^{17,22,23}$. Estes trabalhos consideram o discurso nutricional como uma construção sociocultural ${ }^{15}$ e são adequados para problematizar os discursos que se constroem como recomendações fundamentalmente normativas sobre a comida e o comer. 
Nesta perspectiva, Coveney ${ }^{17}$ considera que a nutrição deve ser pensada como uma ciência que estabelece normas sobre o que se deve comer, mas também como uma ética através da qual os sujeitos se constroem, em relação a estas normas, como um determinado tipo de sujeito. Nesta abordagem, a noção de discurso se refere a um conjunto de saberes e disciplinas historicamente constituídos que representa, em si mesmo, práticas disciplinares. A partir desta leitura foucaultiana, Coveney ${ }^{17}$ indica que os "discursos podem ser entendidos como 'o que limita - mas também permite - escrever, falar e pensar dentro de limites históricos específicos' (McHoul, 1994: 944). Os discursos são, portanto, produtivos no sentido de produzir conhecimentos. De fato, tudo o que é conhecido é tornado conhecido através dos discursos" ${ }^{17}$ (p.4-5) (tradução nossa). O discurso constrói, portanto, uma forma particular de conhecer a realidade e um conjunto de relações de poder ${ }^{20,21}$, reflete entendimentos comuns e os perpetuam, contribuindo para a construção dos modos de pensar e viver ${ }^{18,19}$. Assim, o objeto dos discursos nutricionais tais como a alimentação, o corpo e a saúde, não existe independente do discurso, mas é construído por e através do discurso ${ }^{24}$, assim como é através do discurso que os indivíduos se compreendem a si mesmos, seus corpos e sua relação com a comida ${ }^{18}$.

Portanto, analisar criticamente os discursos nutricionais difundidos por diferentes instituições em uma perspectiva comparativa transnacional é pertinente para compreender o papel das instituições como atores sociais em suas recomendações de saúde em geral e concretamente em relação às práticas alimentares. Cabe, nesse sentido, indagar sobre a construção desses discursos e entender como eles articulam os diferentes modos de vida e as diversidades contextuais presentes nas realidades em que se aplicam. É preciso também verificar como as instituições, na construção de suas políticas, vêm dialogando com a complexidade do ato alimentar, considerando assim as dimensões sociais, econômicas, políticas, simbólicas, éticas etc., imbricadas nos fenômenos alimentares e de saúde.

Como sugerem Lemões et al. ${ }^{25}$, tais reflexões fundamentadas nas perspectivas críticas das ciências humanas e sociais, são necessárias em contextos de crises sanitárias globais que tendem a ocultar as desigualdades e diversidades socioculturais existentes. Ao reproduzir orientações universais e descontextualizadas, instituições internacionais como a Organização Mundial de Saúde e os diferentes governos, costumam considerar a população como um grupo socialmente homogêneo. Nesse sentido, a análise comparativa de guias alimentares, abordagem já efetuada nos campos da nutrição e saúde coletiva ${ }^{10,26-28}$, permite a discussão crítica dos discursos nutricionais, inserindo-os em seus contextos históricos e socioculturais de produção.

Esta análise será realizada considerando elementos teóricos que permitem compreender as relações entre alimentação, nutrição, saúde e cultura. Assim, o pressuposto teórico se centra em textos do campo da socioantropologia da alimentação em geral e concretamente nas discussões sobre medicalização da alimentação ${ }^{29,30}$, cultura alimen$\operatorname{tar}^{6,18,31-33}$ e alimentação saudável ${ }^{15,16,34}$.

\section{Metodologia}

Este estudo, de cunho qualitativo, foi realizado entre maio e agosto de 2020. A pesquisa utilizou como fonte primária de pesquisa dois guias alimentares brasileiros e dois guias espanhóis. A seleção destes guias foi efetuada de acordo com a legitimidade das instituições responsáveis de sua elaboração e a amplitude da sua difusão nos contextos analisados. Além disso, todos estes guias são destinados a população geral, aspecto de interesse, dada a abrangência das recomendações. Todos os documentos foram publicados no mês de março de 2020.

Para a análise dos dados, o estudo baseou-se na Análise do Discurso ${ }^{35}$. Cabe acrescentar que o discurso não só se constitui pela linguagem verbal e, por tanto, a análise também efetuou-se através da leitura das imagens e recursos visuais presentes nos guias, considerando-os como veículos simbó$\operatorname{licos}^{10}$, imagens culturais ${ }^{36}$. A análise dos discursos foi efetuada a partir de categorias analíticas definidas de acordo com os objetivos do estudo e a partir de categorias emergentes das leituras sistemáticas dos guias: estrutura e formato geral das guias; concepções sobre o comer saudável e riscos alimentares; medicalização da alimentação; atribuição de responsabilidade individual; aspectos socioculturais da alimentação; interseccionalidade.

Em relação aos aspectos éticos, de acordo com as normativas brasileiras e espanholas, estudos pautados em análises documentais não necessitam aprovação por comitê de ética ${ }^{37,38}$.

\section{Resultados e discussão}

\section{Apresentação geral dos guias analisados}

Em relação à análise desenvolvida, em um primeiro nível, com o objetivo de descrever as características gerais dos documentos analisados, 
comparou-se seus aspectos formais (Quadro 1). Os quatro guias foram elaborados por entidades do âmbito da alimentação e/ou da nutrição e, em todos os casos, os profissionais envolvidos eram principalmente nutricionistas. Além disso, estes guias foram fundamentados sobretudo em fontes bibliográficas dos campos da nutrição, da medicina e da educação física.

O objetivo dos documentos é a transmissão de informações e recomendações alimentares e nutricionais para fomentar uma alimentação saudável e um bom estado de saúde durante a pandemia de COVID-19. Os documentos salientam a excepcionalidade do contexto, as modificações provocadas nos ritmos de vida e a importân- cia da alimentação para um bom estado de saúde. As recomendações encontram-se principalmente relacionadas com a escolha dos alimentos, preparo e consumo e incluem tanto fatores nutricionais como aqueles associados à higienização dos alimentos. O aleitamento materno é tratado em apenas dois dos documentos (GORAEF e RANPE). Aspectos relacionados com a atividade física também são abordados no GORAEF e QCCB. Além disso, todos os documentos, principalmente o guia RANPE, transmitem conselhos sobre como evitar o contágio de COVID-19.

Embora os objetivos dos guias apresentem similaridades e estejam direcionados sobretudo à população adulta sem patologias, algumas es-

Quadro 1. Características gerais dos guias alimentares analisados.

\begin{tabular}{|c|c|c|c|c|}
\hline & \multicolumn{2}{|r|}{ Brasil } & \multicolumn{2}{|c|}{ Espanha } \\
\hline Título & $\begin{array}{l}\text { Guia para uma } \\
\text { Alimentação } \\
\text { Saudável em } \\
\text { tempos de } \\
\text { COVID-19 }\end{array}$ & $\begin{array}{l}\text { Guia de orientação em } \\
\text { relação à alimentação e } \\
\text { exercício físico diante da } \\
\text { pandemia da doença pelo } \\
\text { SARS-CoV-2 (COVID-19) }\end{array}$ & $\begin{array}{l}\text { \#Quedateencasa- } \\
\text { ComeBien ante } \\
\text { el Coronavirus } \\
\text { SARS-CoV-2 }\end{array}$ & $\begin{array}{l}\text { Recomendaciones de } \\
\text { alimentación y nutrición } \\
\text { para la población } \\
\text { española ante la crisis } \\
\text { sanitaria del COVID-19 } \\
\end{array}$ \\
\hline $\begin{array}{l}\text { Número de } \\
\text { páginas }\end{array}$ & 14 & 19 & 15 & 22 \\
\hline $\begin{array}{l}\text { Mês de } \\
\text { publicação }\end{array}$ & Março & Março & Março & Março \\
\hline $\begin{array}{l}\text { Organismo } \\
\text { responsável }\end{array}$ & $\begin{array}{l}\text { Associação } \\
\text { Brasileira de } \\
\text { Nutrição }\end{array}$ & $\begin{array}{l}\text { Núcleo de Alimentação, } \\
\text { Saúde e Ambiente - Nasa/ } \\
\text { CST/Coordenação de } \\
\text { Saúde do Trabalhador da } \\
\text { Coordenação-Geral de Gestão } \\
\text { de Pessoas (Cogepe)/Fiocruz }\end{array}$ & $\begin{array}{l}\text { Col·legi de } \\
\text { Dietistes- } \\
\text { Nutricionistes } \\
\text { de Catalunya } \\
\text { (CODINUCAT) }\end{array}$ & $\begin{array}{l}\text { Academia Española de } \\
\text { Nutrición y Dietética } \\
\text { y del Consejo General } \\
\text { de Colegios O ciales de } \\
\text { Dietistas-Nutricionistas }\end{array}$ \\
\hline $\begin{array}{l}\text { Profissionais } \\
\text { participantes } \\
\text { na elaboração }\end{array}$ & Nutricionistas & $\begin{array}{l}\text { Profissionais dos campos da } \\
\text { Nutrição e Educação Física }\end{array}$ & Nutricionistas & $\begin{array}{l}\text { Nutricionistas, } \\
\text { enfermeira, biólogo. }\end{array}$ \\
\hline $\begin{array}{l}\text { Fontes de } \\
\text { dados }\end{array}$ & $\begin{array}{l}\text {-American } \\
\text { Society for } \\
\text { Nutrition } \\
\text {-Guia Alimentar } \\
\text { para a População } \\
\text { Brasileira (2014) } \\
\text {-Embrapa }\end{array}$ & $\begin{array}{l}\text {-"Estudos científicos” da área } \\
\text { da Nutrição e atividade física. } \\
\text {-Documentos do Ministerio } \\
\text { da Saúde, incluindo o Guia } \\
\text { Alimentar para a População } \\
\text { Brasileira - 2014. }\end{array}$ & $\begin{array}{l}\text { Informação não } \\
\text { disponibilizada. }\end{array}$ & $\begin{array}{l}\text { "Baseado em uma } \\
\text { revisão científica": } \\
\text { documento cita } 51 \\
\text { referências bibliográficas } \\
\text { principalmente dos } \\
\text { campos da medicina e } \\
\text { nutrição. }\end{array}$ \\
\hline Público-alvo & $\begin{array}{l}\text { População em } \\
\text { geral }\end{array}$ & Trabalhadores da Fiocruz & $\begin{array}{l}\text { População em } \\
\text { geral }\end{array}$ & $\begin{array}{l}\text { População em geral, } \\
\text { pacientes com infecções } \\
\text { leves e graves de } \\
\text { COVID-19 } \\
\end{array}$ \\
\hline Objetivos & $\begin{array}{l}\text { Transmitir } \\
\text { informações/ } \\
\text { recomendações } \\
\text { sobre a } \\
\text { alimentação } \\
\text { saudável no } \\
\text { contexto de } \\
\text { quarentena. }\end{array}$ & \begin{tabular}{|l|}
-Auxiliar trabalhadores \\
e trabalhadoras a se \\
exercitarem e se alimentarem \\
adequadamente no período \\
de isolamento domiciliar para \\
a diminuição dos efeitos da \\
epidemia viral. \\
-Manutenção e obtenção de \\
melhores condições de saúde \\
dos trabalhadores da Fiocruz.
\end{tabular} & $\begin{array}{l}\text { Transmitir } \\
\text { conselhos e } \\
\text { estratégias } \\
\text { para ajudar a } \\
\text { manter, durante } \\
\text { a quarentena, } \\
\text { hábitos } \\
\text { alimentares o } \\
\text { mais saudável } \\
\text { possível. }\end{array}$ & $\begin{array}{l}\text { Transmitir } \\
\text { recomendações } \\
\text { alimentares e } \\
\text { nutricionais para toda } \\
\text { a população espanhola } \\
\text { e também para pessoas } \\
\text { afetadas por COVID-19 } \\
\text { com sintomatologia leve } \\
\text { e/ou assintomática. }\end{array}$ \\
\hline
\end{tabular}


pecificidades devem ser pontuadas. O GORAEF, elaborado por grupos de trabalho da Fundação Oswaldo Cruz, está destinado aos trabalhadores da instituição. Já o documento RANPE também apresenta recomendações para pacientes com infecções de COVID-19.

Finalmente, é necessário indicar que os guias apresentam formatos distintos. Dois guias têm um formato mais técnico e científico, mais textual e menos visual: GORAEF e o guia RANPE. Já os outros guias apresentam formato mais sucinto, visual (com imagens de alimentos e pessoas representados a partir de desenhos simples e coloridos) e linguagem menos técnica.

Neste trabalho, a análise do discurso dos guias alimentares é realizada a partir de três eixos. Primeiro avaliamos como se estruturam as concepções sobre o comer saudável. Para fundamentar essa perspectiva analítico-crítica, questionamos, no segundo eixo, sobre o lugar que a multidimensionalidade da alimentação ocupa nesses documentos. Finalmente, para discutir sobre a inclusão das diversidades contextuais nas recomendações, analisamos, no terceiro eixo, a interseccionalidade (classe, gênero, raça e etnia) ${ }^{39}$.

Cabe considerar, neste momento e para fundamentar nossas reflexões, considerações propostas por Shields-Argelès ${ }^{24}$, que destaca três aspectos teóricos-epistemológicos dos Estudos Críticos de Nutrição/Dietética relevantes para este estudo: (i) a ideia de que a nutrição não representa apenas um conjunto de regras práticas, mas também um sistema moral; (ii) que as estratégias quantitativas supostamente neutras e objetivas da ciência nutricional também servem a fins ideológicos e políticos; (iii) que a nutrição, como um imperativo social e moral que distingue os "bons" e "maus" indivíduos, está enraizada em projetos ideológicos e políticos nacionais.

\section{Norma e discurso: concepções sobre o comer saudável}

Considerando-se as especificidades de cada guia, todos eles reproduzem em geral perspectivas sobre "alimentação saudável" vinculadas à uma ideia biomedicalizada do corpo e da alimentação. Esta perspectiva substitui as racionalidades socioculturais e simbólicas do ato alimentar por uma racionalidade nutricional fundamentada no paradigma positivista, mecanicista e tecnicista moderno que visa a estabelecer práticas alimentares "racionais", baseadas nas recomendações da ciência, e que buscam manter o equilíbrio de nutrientes na alimentação, em detrimento das dimensões socioculturais do comer $^{29-31,34}$. Nesse sentido, a proposta de "recomendação" sobre o que deve ser a comida e as práticas alimentares "ideais" no contexto da pandemia se alinha com uma compreensão sobre o comer saudável principalmente centrada na ingestão "adequada" de nutrientes. Ainda que os guias sustentem um discurso que se orienta ao consumo de alimentos "in natura" em detrimento dos "processados" e "ultraprocessados", o apelo realizado se centra principalmente na dimensão nutricional (rico em fibra, maior valor energético, rico em sódio e calorias etc.), sem que outras problemáticas sociais, éticas, econômicas e ambientais sejam reivindicadas com profundidade. Esta concepção de alimentação saudável, focada na ingestão de nutrientes, se constrói nos discursos a partir do estabelecimento de relações entre alimentação-corpo-doença, com ênfases importantes no peso corporal. Um dos guias refere-se inclusive à expressão "nossos pacientes"12 situando os sujeitos do discurso nesse status. O lugar dos leitores-interlocutores é o lugar do sujeito-paciente que lê e absorve de forma não horizontal a informação científica trazida nos guias. O Quadro 2 ilustra alguns exemplos de discursos quanto a estes aspectos.

Um dado importante sobre essa questão é a relevância que os profissionais do campo biomédico têm na elaboração dos guias analisados, não havendo referência à expansão do diálogo intersetorial ou interprofissional na construção dos discursos. Não há, por exemplo, interlocução com profissionais das ciências humanas e sociais. Esse dado é relevante na condução das abordagens sobre a compreensão que reproduzem sobre o que é a comida, o comer, o corpo, a saúde, por exemplo, consolidando-se, portanto, a perspectiva biomedicalizada referida. Cabe destacar que a formação destes profissionais do campo biomédico - como os da Nutrição que ocupam um lugar central na elaboração destes guias -, apresenta um perfil fundamentalmente técnico e biológico ${ }^{40,41}$, que frequentemente não considera a multidimensionalidade e complexidade das problemáticas de saúde, corpo e alimentação, especialmente o papel dos fatores sociais e culturais.

Assim, o discurso sobre "como comer" se constrói de forma normativa, estruturando-se em função de formas linguísticas imperativas em muitos casos (Quadro 2). Além disso, esta linguagem é por vezes "negativa" e verbos como "evite" e "limite" são usados para compor essas recomendações. O indivíduo é incentivado repetidamente a incorporar protocolos e disciplinas que favoreçam a moderação e o controle alimentar. Estas formas linguísticas e os próprios conteúdos dos guias também são reveladores do 


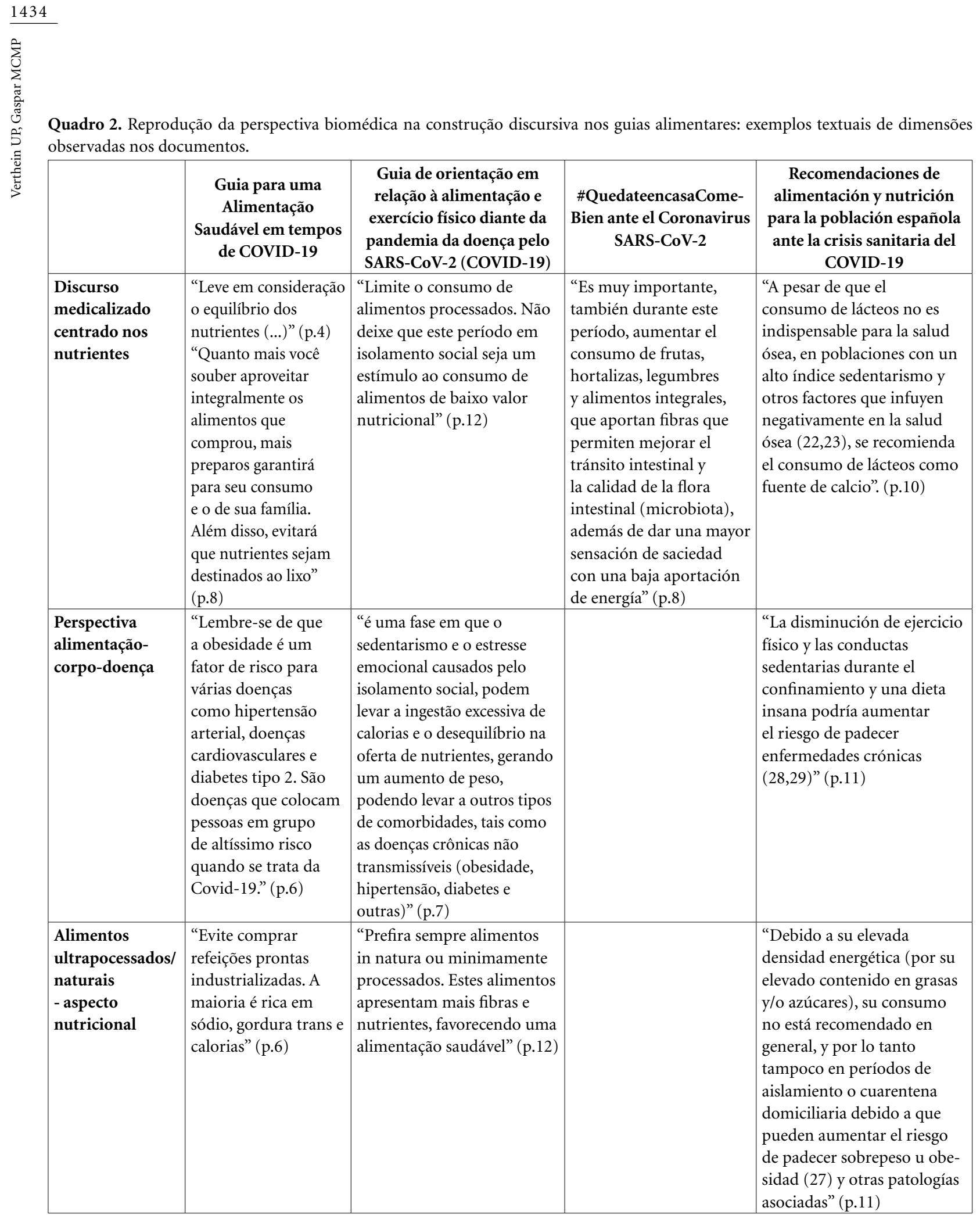

continua

posicionamento priorizado nos discursos sobre "alimentação saudável" no que se refere à centralidade do indivíduo e sua responsabilização sobre as práticas corporais e alimentares consideradas “corretas" ou "incorretas". Essa questão estrutural permeia o discurso dos guias analisados de forma expressiva e pode ser identificada com clareza em situações concretas que estimulam práticas disciplinares. Isso ocorre por exemplo na reprodução da ideia de que "comer bem" não depende neces- 
Quadro 2. Reprodução da perspectiva biomédica na construção discursiva nos guias alimentares: exemplos textuais de dimensões observadas nos documentos.

\begin{tabular}{|c|c|c|c|c|}
\hline & $\begin{array}{c}\text { Guia para uma } \\
\text { Alimentação } \\
\text { Saudável em tempos } \\
\text { de COVID-19 }\end{array}$ & $\begin{array}{l}\text { Guia de orientação em } \\
\text { relação à alimentação e } \\
\text { exercício físico diante da } \\
\text { pandemia da doença pelo } \\
\text { SARS-CoV-2 (COVID-19) }\end{array}$ & $\begin{array}{c}\text { \#QuedateencasaCome- } \\
\text { Bien ante el Coronavirus } \\
\text { SARS-CoV-2 }\end{array}$ & $\begin{array}{l}\text { Recomendaciones de } \\
\text { alimentación y nutrición } \\
\text { para la población española } \\
\text { ante la crisis sanitaria del } \\
\text { COVID-19 }\end{array}$ \\
\hline \begin{tabular}{l|} 
Discursos \\
imperativos \\
/ Fomento da \\
responsabilidade \\
individual
\end{tabular} & $\begin{array}{l}\text { O título do guia: } \\
\text { "QuedateencasaCo- } \\
\text { meBien" } \\
\text { "Minimize a ida aos } \\
\text { centros de abasteci- } \\
\text { mento durante a pan- } \\
\text { demia e se alimente } \\
\text { de forma saudável" } \\
\text { (p.6) } \\
\text { "Não coloque em ris- } \\
\text { co pessoas e objetos } \\
\text { desinfectados" (p.7) }\end{array}$ & $\begin{array}{l}\text { "Movimente- se!” (p.6) } \\
\text { "Alimentos processados. } \\
\text { Limite o uso destes } \\
\text { alimentos" (p.7) } \\
\text { "é importante também que } \\
\text { trabalhadores da instituição } \\
\text { que estão trabalhando em } \\
\text { home office, possam ficar } \\
\text { atentos quanto aos possíveis } \\
\text { estímulos referentes } \\
\text { ao consumo alimentar } \\
\text { excessivo. (...)" (p.15) }\end{array}$ & $\begin{array}{l}\text { "Prioriza alimentos ricos } \\
\text { en fibra" (p.8) } \\
\text { "Activate" (p.12) }\end{array}$ & $\begin{array}{l}\text { "Coma pelo menos } 5 \\
\text { porções de frutas ou } \\
\text { verduras por dia" (p.9) }\end{array}$ \\
\hline
\end{tabular}

sariamente da relação da comida com as dimensões sociais e ambientais, mas é uma questão de escolha individual (ou do núcleo familiar) sobre que nutrientes devem ser "ingeridos". Por isso, as recomendações são construídas quase sempre como "conselhos" para pessoas ou famílias, onde ocorre por vezes um esvaziamento da dimensão macrossocial e política da alimentação e da vida. "Escolher o consumo de produtos integrais", "Escolher produtos lácteos baixos em gordura”, optar por um "Consumo moderado de outros alimentos de origem animal dentro das recomendações saudáveis", são propostas dirigidas à modificação de "hábitos" individuais.

Nesta perspectiva, estas modificações alimentares dependeriam de competências dietéticas incorporadas a partir das informações transmitidas nos guias e do esforço pessoal. Essa abordagem, frequente nas políticas públicas em matéria de nutrição e "luta" contra a obesidade, baseia-se em um perfil idealizado de comensal que teria livre escolha sobre sua alimentação ${ }^{29,42}$. Tal ideologia da saúde culpa os indivíduos de suas doenças ou "anormalidades" e apresenta um apelo moral estruturado em torno aos preceitos de autocontrole e autorregulação ${ }^{43}$. Segundo Germov e Williams ${ }^{42}$, esta teoria "ignora o potencial de que as escolhas (alimentares) sejam manipuladas, condicionadas ou determinadas pela localização social de um indivíduo ou por desigualdades na estrutura social, particularmente para grupos marginalizados"42(p.103) (tradução nossa).

É por essa opção epistemológica - que centra na responsabilidade individual as problemáti- cas alimentares e que, por isso, esvazia possíveis causalidades estruturais - que, no contexto da pandemia, a alimentação pode acabar assumindo um lugar como o de "prevenção do adoecimento pelo fortalecimento da imunidade". Nessa linha interpretativa é na imunidade do indivíduo que ela age e atua, porque não se vincula obrigatoriamente com os questionamentos sobre os processos de produção, distribuição e consumo dos alimentos que consumimos e suas relações com o entorno social. Assim, entre os textos analisados, ainda que em algumas ocasiões advertissem sobre a inexistência de evidências científicas concretas sobre a relação entre a alimentação saudável e a prevenção de contágio ou não agravamento do adoecimento em casos de COVID-19, nos dois guias brasileiros foram encontrados alguns fragmentos que propunham essa relação causal: "Uma alimentação saudável é primordial para manter a saúde e é especialmente importante para manter seu sistema imunológico em ótimas condições, sem esquecer das medidas de higiene necessárias para evitar as contaminações” ${ }^{12}$ (p.3).

A alimentação é, portanto, muitas vezes reduzida a um fator de risco relacionado com a COVID-19, mas também com a obesidade e outras doenças crônicas, que também se tornaram, no contexto da pandemia, fatores de risco para $\mathrm{CO}$ VID-19. Nesta linha discursiva, as concepções de risco presentes nos guias -centradas sobre o indivíduo- consideram principalmente sua saúde física (em detrimento da mental e social), relacionada sobretudo com as dimensões nutricionais e bacteriológicas. 


\section{O lugar da multidimensionalidade da alimentação}

Pelo exposto, faz-se então necessário discutir que lugar ocupa a multidimensionalidade da alimentação na compreensão sobre o "comer saudável" e analisar em que medida os guias alimentares dialogam com a complexidade do ato alimentar ${ }^{6,32}$ para informar, recomendar ou indicar diretrizes sobre aspectos relacionados com a comida e o comer. As recomendações propostas atravessam campos diversos da alimentação, como a origem dos produtos, a compra de alimentos, o preparo cotidiano de comida, o consumo, a comensalidade, a higiene, por exemplo. É, portanto, pela amplitude de âmbitos alcançados, em suas propostas de construção de diretrizes, que a relevância dos aspectos sociais, políticos, econômicos, emocionais e culturais precisam assumir centralidade no discurso.

A análise dos guias revelou que, para além da dimensão biológica, a multidimensionalidade da alimentação está presente nos documentos através de diferentes meios, ainda que de forma pouco complexa (Quadro 3).

É expressiva a necessidade de aprofundamento das referidas questões nos textos para uma construção efetivamente complexa do que é o comer saudável. Na totalidade dos guias, as dimensões sociocultural, emocional, econômica ou política do ato alimentar não são suficientemente presentes para problematizar a hegemonia da dimensão biológica e biomédica do comer. A noção de saúde é então fundamentalmente conduzida dentro dessa linha interpretativa e não dialoga verdadeiramente com os demais campos de interlocução que a alimentação interage e que devem constituir eixos centrais de qualquer recomendação nutricional e alimentar. Como a antropologia da alimentação vem reafirmando nas últimas décadas, o ato alimentar, para além do nutrir, é um fenômeno biopsicosociocultural. Este ato deve, portanto, ser pensado como uma ação também simbólica na qual não se ingere somente nutrientes, mas que está permeada por significados compartilhados socialmente ${ }^{6,32}$.

Sobre essa questão, cabe considerar que uma análise crítica de políticas públicas de alimentação e nutrição ${ }^{33}$ já havia identificado que a referência aos aspectos multidimensionais da alimentação, como a cultura alimentar, nos artigos científicos sobre educação alimentar e nutricional, não corresponde necessariamente com um efetivo aprofundamento sobre as questões nesse sentido. Revela-se, pelo exposto, como desafio para o campo, a necessidade de consolidação e legitimação de suas bases teóricas e epistemológicas.

Nos guias analisados, essa questão revela-se no esvaziamento dos sentidos e significados da multidimensionalidade da alimentação e na sua consequente apropriação para aplicação do discurso normativo-prescritivo sobre o comer saudável. Nos guias brasileiros, por exemplo, apesar da referência ao Guia Alimentar para a População Brasileira (GAPB $)^{44}$, desconsidera-se a importância da complexidade do ato alimentar que este documento defende com clareza. A utilização do GAPB serve, portanto, fundamentalmente como referência para a classificação de alimentos, recomendação de consumo de determinados produtos ou priorização de determinadas técnicas culinárias, mas quase sempre mantendo como perspectiva discursiva a vertente nutricional.

Nos guias espanhóis, as questões ambientais relacionadas ao consumo alimentar parecem mais presentes, mas a importância da cultura alimentar como dimensão legítima tem também pouco peso. No discurso sobre o "saudável", a cultura, a tradição, as práticas alimentares associadas com a identidade (nesse caso, a Dieta Mediterrânea) são desconsideradas em algumas ocasiões, em prol de uma adequação ao que se considera como um "padrão alimentar saudável". Nesse caso, o consumo de vinho ou cerveja, "apesar de" ser reconhecido pelo guia como parte da cultura alimentar na Espanha, "não se recomenda":

A pesar de que el consumo moderado de alcohol (vino y cerveza) se reconozca como parte del patrón alimentario, debido a sus posibles efectos beneficioso no están tan claros, y que además existen potenciales efectos adversos, no se recomienda su consumo dentro de un patrón alimentario saludable ${ }^{14}(\mathrm{p} .8)$.

Cabe ainda destacar que de forma geral, em todos os guias, as dimensões hedonista e emocional do ato alimentar são marginalizadas e, com frequência, quando mencionadas, o foco da atenção se desloca sobre possíveis fatores negativos a elas associados: o comer em excesso, a "tentação" ou a falta de controle. Desta forma, em um contexto de incertezas, medos e angústias, no qual as dimensões hedonista e emocional do ato alimentar tornaram-se fundamentais para a população ${ }^{1}$ os guias não consideram a saúde e sua relação com a alimentação de forma holística, tal como o contexto demanda:

Durante esta situación especial que estamos viviendo, la tentación por los alimentos dulces, chucherias, snacks, bebidas azucaradas, bollería, etc., puede ser mayor. Si hace falta, reserva espacios muy concretos para estas ingestas: aperitivos del domingo, cena del sábado, alguna merienda o 
Quadro 3. Principais elementos da multidimensionalidade do ato alimentar mencionados pelos guias alimentares analisados.

\begin{tabular}{|c|c|}
\hline Guia alimentar & Principais elementos da multidimensionalidade do ato alimentar mencionados \\
\hline $\begin{array}{l}\text { Guia para uma } \\
\text { Alimentação } \\
\text { Saudável em } \\
\text { tempos de } \\
\text { COVID-19 }\end{array}$ & $\begin{array}{l}\text {-Pandemia e novas formas de vida: reconfiguração dos usos do tempo, adaptações da } \\
\text { rotina, reorganização do trabalho doméstico, por exemplo. } \\
\text {-Referência à políticas públicas de alimentação que consideram a multimensionalidade } \\
\text { (GAPB); } \\
\text {-Importância da atividade culinária doméstica; } \\
\text {-Educação e interdisciplinaridade através da atividade culinária com crianças; } \\
\text {-Recomendação sobre necessidade de perspectiva crítica sobre informação (propagandas); } \\
\text {-Comensalidade (lugar e funções das relações sociais que se estabelecem na hora de comer) } \\
\text { no contexto da pandemia. }\end{array}$ \\
\hline $\begin{array}{l}\text { Guia de } \\
\text { orientação } \\
\text { em relação à } \\
\text { alimentação } \\
\text { e exercício } \\
\text { físico diante } \\
\text { da pandemia } \\
\text { da doença pelo } \\
\text { SARS-CoV-2 } \\
\text { (COVID-19) }\end{array}$ & $\begin{array}{l}\text {-Pandemia e novas formas de vida (reconfiguração dos usos do tempo, adaptações da } \\
\text { rotina, reorganização do trabalho doméstico, por exemplo). } \\
\text { - Referência a políticas públicas de alimentação que consideram a multimensionalidade } \\
\text { (GAPB); } \\
\text {-Importância da atividade culinária doméstica; } \\
\text {-Sazonalidade dos alimentos em suas relações com o ambiente e a saúde; } \\
\text { - Compra e consumo ambiental e socialmente responsável (sazonalidade, compra de } \\
\text { alimentos in natura, por exemplo). } \\
\text {-Comensalidade (lugar e funções das relações sociais que se estabelecem na hora de comer) } \\
\text { no contexto da pandemia. }\end{array}$ \\
\hline $\begin{array}{l}\text { \#Quedateenca- } \\
\text { saComeBienan- } \\
\text { teelCoronavirus } \\
\text { SARS-CoV-2 }\end{array}$ & $\begin{array}{l}\text {-Pandemia e novas formas de vida (reconfiguração dos usos do tempo, adaptações da } \\
\text { rotina, reorganização do trabalho doméstico, por exemplo). } \\
\text {-Compra e consumo ambiental e socialmente responsável (prioridade a produtos de } \\
\text { proximidade e de temporada, redução do uso de plásticos e embalagens, redução de } \\
\text { desperdício, por exemplo); } \\
\text {-Comensalidade no contexto da pandemia (lugar e funções das relações sociais que se } \\
\text { estabelecem na hora de comer) no contexto da pandemia. } \\
\text {-Sazonalidade dos alimentos em suas relações com o ambiente e a saúde; } \\
\text { - Prazer de comer/Alimentação "extra". } \\
\text {-Cultura alimentar (Dieta mediterrânea, consumo de azeite de oliva, por exemplo). }\end{array}$ \\
\hline $\begin{array}{l}\text { Recomendaciones } \\
\text { de alimentación } \\
\text { y nutrición para } \\
\text { la población } \\
\text { española ante la } \\
\text { crisis sanitaria del } \\
\text { COVID-19 }\end{array}$ & $\begin{array}{l}\text {-Pandemia e novas formas de vida: reconfiguração dos usos do tempo, adaptações da } \\
\text { rotina, reorganização do trabalho doméstico, por exemplo. } \\
\text {-Cultura alimentar (Dieta mediterrânea); } \\
\text {-Questões econômicas adaptadas ao consumo (possibilidade de acesso); } \\
\text {-Compra e consumo ambiental e socialmente responsável (prioridade a produtos de } \\
\text { proximidade e de temporada, redução do uso de plásticos e embalagens, por exemplo) }\end{array}$ \\
\hline
\end{tabular}

almuerzo, para ayudar a marcar la diferencia con el resto de comidas más saludables ${ }^{13}$ (p.9).

\section{A interseccionalidade e o discurso sobre o comer saudável: norma e desigualdades sociais}

$\mathrm{Na}$ perspectiva crítica deste estudo, cabe discutir se os guias assumem de forma adequada e com suficiente complexidade a questão interseccional - classe, gênero, etnia e raça - na construção discursiva sobre o comer saudável. Questionamos se as desigualdades sociais -estruturalmente presentes e agravadas no contexto da pandemia nos dois países- estão suficientemente inseridas e problematizadas nos textos.

Nessa abordagem, constatou-se que os textos são construídos fundamentalmente para um público leitor restrito. Os processos de precarização da vida não estão claramente expostos nos textos e as recomendações desconsideram muitas vezes as circunstâncias de empobrecimento da população no contexto da pandemia ou as contingências estruturais da população pobre dos dois países.

Uma questão fundamental a esse respeito é que a problemática da fome e da SAN, agravadas pela pandemia ${ }^{2-4}$, não são abordadas com profundidade nos guias. As palavras e expressões "fome" 
ou "hambre", "segurança alimentar e nutricional" ou "seguridad alimentaria y nutricional", "direito" ou "derecho", "desnutrição" ou "desnutrición" não são mencionadas. Os guias alimentares deveriam exercer um papel mais explícito e decisivo na SAN, considerando esta última de forma holística, complexa e crítica ${ }^{44}$. Nos guias analisados, percebe-se que a importância da dimensão política relacionada com a SAN, de forma geral, e com o combate à fome e o direito à alimentação, de forma particular, poderia ser incorporada de forma mais complexa nos discursos. Assim, os guias se atêm sobre esse aspecto fundamentalmente em relação à obesidade e doenças crônicas não transmissíveis, com ênfase na normativização das formas corporais; não considerando com complexidade os determinantes sociais que incidem sobre a ocorrência desses fenômenos.

Além disso, as recomendações muitas vezes partem do pressuposto de que as pessoas e famílias terão disponibilidade temporal e condições materiais e financeiras de comprar, cuidar, trabalhar, se exercitar, o que não corresponde com as realidades sociais dos dois países em questão. Embora os guias QCCB e GORAEF adotem uma linguagem inclusiva quanto ao gênero, as questões de gênero, como a sobrecarga assumida pelas mulheres no contexto da pandemia ${ }^{1}$, também não surgem como elementos centrais nos discursos. Questões como a vulnerabilidade e a saúde da população negra também não estão expressas com a relevância que precisam ter. Esta população não está inclusive representada nas imagens propostas nos guias. Nesse sentido nos perguntamos: para quem o discurso do comer saudável está sendo construído? Quem pode cumprir as recomendações propostas? Consideramos que nos casos analisados, o direito ao saudável está sendo construído e conduzido de forma excludente. Por exemplo: no documento GAS ${ }^{12}$, após o título: "Vamos planejar. Prepare as principais refeições de forma equilibrada" ${ }^{12}$ (p.4), surge a imagem de uma família branca heterosexual composta por um homem (pai), uma mulher (mãe) e uma criança pequena. A família cozinha feliz em uma cozinha equipada com eletrodomésticos e utensílios. Discutimos, portanto, a pertinência dessa imagem, dada a diversidade, por um lado, $\mathrm{e}$ as desigualdades sociais no Brasil, por outro. $\mathrm{O}$ discurso sobre o saudável não aprofunda assim discussões urgentes em relação à interseccionalidade, a saúde e a alimentação construídas na atualidade por diversos atores da sociedade civil.

O GORAEF ${ }^{11}$, em suas recomendações sobre exercício físico, afirma: "Procure a orientação de um profissional de Educação Física. Ele saberá prescrever a melhor estratégia de treinos de acordo com o seu nível de condicionamento e suas limitações"11(p.6). Questiona-se a possibilidade de que parte da população pague pelos serviços de profissionais dessa área para se exercitar cotidianamente. Além disso, o fragmento a seguir revela, na mesma perspectiva, a dimensão referida:

Com base nos alimentos disponíveis em casa e no quadro da categorização dos alimentos é possível planejar as refeições, por exemplo, se em casa há pedaços de legumes e verduras que estão em bom estado, podemos transformá-los em um ratatouille (legumes refogados, assados e bem temperados). Caso seja necessário, para elaboração das receitas culinárias, utilize a internet para procurar sites sobre a temática, é uma ótima forma de desenvolver as habilidades culinárias ${ }^{11}(\mathrm{p} .8)$.

Problematiza-se, nesse trecho, a pertinência do exemplo da preparação do ratatouille como prato representativo da cultura alimentar brasileira. Como nos outros guias analisados, a regionalidade é pouco considerada. Além disso, a recomendação do acesso à internet (também presente nos outros guias) não é factível para setores da população excluídos do acesso a plataformas digitais.

No caso dos guias espanhóis, ocorre também a invisibilização da pobreza e dos processos de precarização da vida, tanto em relação às suas formas estruturais, quanto em relação ao seu agravamento durante a pandemia. Por exemplo, o guia QCCB $^{13}$ constrói suas recomendações a partir de uma compreensão sobre o uso do tempo que desconsidera a complexidade das realidades sociais no país. Como no fragmento:

Este confinamiento puede ser una oportunidad para probar, practicar y enseñar a compañeras y compañeros y/o a los más pequeños de la casa, la preparación de muchos platos que, en otras ocasiones, el tiempo no nos permite. Utiliza nuevas recetas y disfruta de la alimentación saludable ${ }^{13}(\mathrm{p} .11)$.

Questiona-se, no trecho, sobre que projeção sobre as rotinas dos diferentes grupos populacionais se construíram nos guias analisados, em diferentes sentidos. Primeiro sobre a possibilidade de permanecer em casa e de "ter mais tempo" para realizar tarefas domésticas. Além disso, a opção de aprender e ensinar aos familiares a cozinhar, como uma demanda adicional. Nesse caso, é importante considerar a informação de que as mulheres tiveram, no período da pandemia, um aumento do tempo dedicado ao cuidado de pessoas e à realização de trabalho doméstico, o que acarretou aumento de estresse, ansiedade e consequências negativas para sua saúde física e emocional ${ }^{1}$. 


\section{Considerações finais}

Este estudo reconhece a importância dos guias alimentares como estratégia política para difusão do conhecimento sobre "alimentação saudável". Os guias possuem uma função social de grande importância para informação da população sobre as práticas alimentares e corporais em suas relações com a saúde, a SAN e o bem-estar das pessoas e grupos. Especialmente, destaca-se o valor da construção desses textos em situações de crise sanitária, como a pandemia de COVID-19. Os guias, nesses contextos, caracterizam-se como ferramentas fundamentais para o esclarecimento de dúvidas e incertezas a respeito da alimentação, naturalmente agravadas nesses períodos. Pelo dito, e exatamente pela importância que têm os guias alimentares, em geral, e em contextos particulares, como a atual pandemia, é fundamental destacar a pertinência de uma análise crítica desses documentos. Os elementos de reflexão propostos são necessários para o enriquecimento e aprofundamento dos discursos que reproduzem.

Os documentos analisados, produzidos em contextos nacionais diferentes (Brasil e Espanha), apresentam diferenças gerais em relação à forma. Quanto aos países de produção, encontrou-se coincidências diversas em relação aos conteúdos das recomendações, entre os dois guias produzidos no Brasil e os dois guias produzidos na Espanha. No entanto, apesar das diferenças identificadas, constatou-se que os discursos dos quatro guias se alinham na compreensão que reproduzem sobre o que é o "comer saudável" e na maneira como a retórica das recomendações é exercida e remetida à população. A construção discursiva fomenta a normatização sobre o comer e reproduz uma perspectiva fundamentalmente biomédica sobre as práticas alimentares e corporais, sem considerar com suficiente profundidade a multidimensionalidade da alimentação e as especificidades micro e macrossociais que influenciam o ato alimentar. No mesmo sentido, revela-se a necessidade da inclusão das dimensões interseccionais de gênero, raça, etnia e classe nas recomendações propostas nos documentos.

Nesse caminho, que aborda a distância entre produtores do discurso sobre o "comer saudável" e seus interlocutores, cabe discutir, os processos de distanciamento que se constroem em função de um propósito de "recomendar", "orientar" ou "informar" o público "leigo". Por isso, é pertinente discutir se canais de diálogo e dialogicidade estão sendo propostos no contexto de produção desses documentos, inclusive para se pensar sobre a viabilidade de cumprimento das recomendações que estão sendo divulgadas.

\section{Colaboradores}

UP Verthein e MCMP Gaspar participaram da elaboração do estudo, da coleta e análise dos dados e redação do artigo.

\section{Referências}

1. Gaspar MCMP, Ruiz M, Begueria A, Anadon S, Barba A, Larrea-Killinger C. Comer en tiempos de confinamiento: gestión de la alimentación, disciplina y placer. Periferia 2020; 25(2):63-73.

2. Freitas MCS, Pena PGL. Fome e pandemia de COVID-19 no Brasil. Tessituras 2020; 8(S1):34-40.

3. Oliveira TC, Abranches MV, Lana RM. (In)Segurança alimentar no contexto da pandemia por SARS-CoV-2. Cad Saúde Pública 2020; 36(4):e00055220.

4. Blanco LF, Sacramento J. O que nos espera depois da pandemia? Boletim Cientistas Sociais n. 47 [Internet]. 2020 [acessado 2020 Jul 12]. Disponível em: https:// sbpcsc.ufsc.br/files/2020/04/Boletim-47.pdf

5. Muscogiuri G, Barrea L, Savastano S, Colao A. Nutritional recommendations for CoVID-19 quarantine. Eur J Clin Nutr 2020; 74:850-851.

6. Fischler C. L'Homnivore. Paris: Odile Jacob; 1990.

7. World Health Organization (WHO). Food and Nutrition Tips During Self-Quarantine [Internet]. 2020 [acessado 2020 Jul 12]. Disponível em: https://www. euro.who.int/en/health-topics/health-emergencies/ coronavirus-covid-19/technical-guidance/food-and -nutrition-tips-during-self-quarantine 
8. Castro IRR, Castro LMC, Gugelmim A. Ações educativas, programas e políticas envolvidos nas mudanças alimentares. In: Diez-Garcia RW, Cervato-Mancuso AM. Mudanças alimentares e educação nutricional. Rio de Janeiro: Guanabara Koogan; 2012. p. 18-34.

9. Barbosa RMS, Colares LGT, Soares EA Desenvolvimento de guias alimentares em diversos países. Rev Nutr 2008; 21:455-467.

10. Oliveira MSS, Arceño MA, Sato PM, Scagliusi FB. Comparison of government recommendations for healthy eating habits in visual representations of food -based dietary guidelines in Latin America. Cad Saúde Pública 2019; 35(12):e00177418.

11. Núcleo de Alimentação, Saúde e Ambiente (Nasa/ CST/Cogepe/Fiocruz). Guia de Orientação em Relação à Alimentação e Exercício Físico diante da COVID-19. Rio de Janeiro: Fiocruz; 2020.

12. Associação Brasileira de Nutrição (ASBRAN). Guia para uma Alimentação Saudável em tempos de COVID-19. São Paulo: ASBRAN; 2020.

13. Colegio de Dietistes-Nutricionistes de Catalunya (CODINUCAT). \#QuedateencasaComeBien Ante el Coronavirus SARS-CoV-2. Barcelona: CODINUCAT; 2020.

14. Academia Española de Nutrición y Dietética. Recomendaciones de alimentación y nutrición para la población española ante la crisis sanitaria del COVID-19. Barcelona: Academia Española de Nutrición y Dietética; 2020.

15. Gaspar MCMP, Muñoz A, Larrea-Killinger C. How would you define healthy food? Social representations of Brazilian, French and Spanish dietitians and young laywomen. Appetite 2020; 153:104728.

16. Azevedo E. Reflexões sobre riscos e o papel da ciência na construção do conceito de alimentação saudável. Rev Nutr 2008; 21(6):717-723.

17. Coveney J. Food, Morals and Meaning: The Pleasure and anxiety of eating. London/New York: Routledge; 2006.

18. Lupton D. Food, the body and the self. London: Sage; 1996.

19. Lupton D. Fat. London/New York: Routledge; 2013.

20. Foucault M. El orden del discurso. Barcelona: Tusquets Editores; 2018.

21. Foucault M. La arqueología del saber. Madrid: Siglo XXI; 2009.

22. Biltekoff C. Critical Nutrition Studies. Oxford: Oxford University Press; 2012.

23. Coveney J, Booth S. Critical Dietetics and Critical Nutrition Studies. Cham: Springer; 2019.

24. Shields-Argelès C. Du discours au récit. Approche comparative du rapport entre alimentation et constructions identitaires en France et aux États-Unis. PhD, EHESS, France; 2012.

25. Lemões T, Aderaldo G, Menasche R. Vozes inquietas em tempos brutos. $\mathrm{O}$ que as ciências sociais têm a dizer? Tessituras 2020; 8(S1):1-7.

26. Sichieri R, Chiuve SE, Pereira RA, Lopes ACS, Willett WC. Dietary recommendations: comparing dietary guidelines from Brazil and the United States. Cad Saude Publica 2010; 26(11):2050-2058.

27. Andrade LM, Bocca C. Análise comparativa de guias alimentares: proximidades e distinções entre três países. Demetra 2016; 11(4):1001-1016.
28. Menezes MFG, Prado SD, Gracia-Arnaiz M, Carvalho MCVS. Homogeneidade, controle e risco na alimentação saudável para idosos: análise comparativa das proposições das agendas públicas brasileira e espanhola. In: Prado SD, Amparo-Santos L, Silvia LF, Gracia-Arnaiz M, Bosi MLM. Estudos socioculturais em alimentação: saberes em rede. Rio de Janeiro: Editora da UERJ; 2016. p. 427-458.

29. Gracia-Arnaiz M. Comer bien, comer mal: la medicalización de la alimentación. Salud Pública Mex 2007; 49(3):236-242.

30. Viana MR, Neves AS, Camargo Junior KR, Prado SD, Mendonça ALO. A racionalidade nutricional e sua influência na medicalização da comida no Brasil. Cien Saude Colet 2017; 22(2):447-456.

31. Poulain JP. Manger Aujourd'hui: attitudes, normes et pratiques. Toulouse: Privat; 2002.

32. Contreras J, Gracia-Arnaiz M. Alimentación y cultura. Perspectivas antropológicas. Barcelona: Ariel; 2005.

33. Verthein UP, Santos LAS. A noção de cultura alimentar em ações de Educação Alimentar e Nutricional em escolas Brasileiras: Uma análise crítica. Cien Saude Colet 2020 [no prelo].

34. Kraemer FB, Prado SD, Ferreira FR, Carvalho MCVS. O discurso sobre a alimentação saudável como estratégia de biopoder. Physis 2014; 24(4):1337-1359.

35. Orlandi E. Análise de discurso: princípios \& procedimentos. Campinas: Pontes; 2009.

36. Hockings P, Tomaselli KG, Ruby J, MacDougall D, Williams D, Piette A. Where is the theory in visual anthropology? Vis Anthropol 2014; 27:436-456.

37. Universidad de Barcelona. Código de buenas prácticas en investigación. Barcelona: Agència de Polítiques i de Qualitat UB. Barcelona: Universidad de Barcelona; 2010.

38. Brasil. Ministério da Saúde (MS). Resolução no 466, de 12 de dezembro de 2012. Diário Oficial da União 2013; 24 jul.

39. Akotirene C. Interseccionalidade. São Paulo: Pólem; 2019.

40. Silva BL, Cantisani JL. Interfaces entre a gordofobia e a formação acadêmica em nutrição: um debate necessário. Demetra 2018; 13(2):363-380.

41. Fonseca AB, Frozi, DS. Social and Natural Sciences in Nutrition: studying the opinion of undergraduates from Brazil and Spain. RACA 2019; 1(1):28-45.

42. Germov J, Williams L. The epidemic of dieting women: The need for a sociological approach to food and nutrition. Appetite 1996; 27:97-108.

43. Crawford R. You are dangerous to your health: The ideology and politics of victim blaming. Int $J$ Health Serv 1977; 7:663-680.

44. Brasil. Ministério da Saúde (MS). Guia Alimentar para a População Brasileira. Brasília: MS; 2014.

Artigo apresentado em 25/09/2020

Aprovado em 21/12/2020

Versão final apresentada em 23/12/2020

Editores-chefes: Romeu Gomes, Antônio Augusto Moura da Silva 


\title{
ERRATA
}

p. 1429,

onde se lê:

Standardizing eating habits: a critical analysis of Brazilian and Spanish food norms in the context of the COVID-19 pandemic

\begin{abstract}
In response to the health, social, economic and political impacts caused by the COVID-19 pandemic, several countries have adopted social isolation as a preventive measure. The concern with "healthy" eating was accentuated in this context and food norms were developed as an orientation strategy related to eating habits. The scope of this article is to carry out a critical and comparative analysis of four food guidelines published in Brazil and Spain in this period, based on three principles: concepts regarding healthy eating; the place attributed to the multidimensionality of the act of eating; and the relevance of intersectionality. Comparison of the documents was conducted using a qualitative approach based on discourse analysis. The documents feature differences in terms of the format and content of the recommendations, but the discursive construction of all the guidelines is normative and reproduces a fundamentally biomedical perspective centered on nutrients and on individual responsibility, without taking into consideration the multidimensionality of the act of eating and the specificities of the micro-and macrosocial contexts. The analysis also reveals the need to include the intersectional dimensions of gender, race, ethnicity and class into the proposed recommendations.
\end{abstract}

Key words Healthy eating, Food norms, COVID-19, Medicalization, Intersectionality

leia-se:

\section{Standardizing eating habits: a critical analysis of Brazilian and Spanish food guides in the context of the COVID-19 pandemic}

Abstract In response to the health, social, economic and political impacts caused by the COVID-19 pandemic, several countries have adopted social isolation as a preventive measure. The concern with "healthy" eating was accentuated in this context and food guides were developed as an orientation strategy related to eating habits. The scope of this article is to carry out a critical and comparative analysis of four food guidelines published in Brazil and Spain in this period, based on three principles: concepts regarding healthy eating; the place attributed to the multidimensionality of the act of eating; and the relevance of intersectionality. Comparison of the documents was conducted using a qualitative approach based on discourse analysis. The documents feature differences in terms of the format and content of the recommendations, but the discursive construction of all the guidelines is normative and reproduces a fundamentally biomedical perspective centered on nutrients and on individual responsibility, without taking into consideration the multidimensionality of the act of eating and the specificities of the micro-and macrosocial contexts. The analysis also reveals the need to include the intersectional dimensions of gender, race, ethnicity and class into the proposed recommendations.

Key words Healthy eating, Food guides, COVID-19, Medicalization, Intersectionality 